\title{
SOLUTION REPERTOIRE
}

\author{
Koen VAN TURNHOUT and Aletta SMITS \\ Utrecht University of Applied Sciences, The Netherlands
}

\begin{abstract}
In this paper, we argue that design 'solutions' such as iconic designs, archetypes and design patterns, ought to be recognized as crucial forms of design knowledge. There is an abundance of literature suggesting solutions play a crucial role in design cognition: they can act as a gateway to understand the design situation better, as a stepping-stone to novel ideas and as an illustration of good practices. Unfortunately, however, the question of what this means for our teaching and our curriculum design has received less attention. How should instructors and design programmers handle solution-oriented knowledge? To spark a more informed debate about teaching solution-oriented thinking, we introduce the notion of solution repertoire: "the competence of appreciating and handling solutions in one's design discipline and to use them as an anchor point for design-relevant knowledge that goes beyond the anecdotal experience". This paper sets the stage by introducing and defining solution repertoire and by examining the implications of way of thinking for our own curriculum.
\end{abstract}

Keywords: Solution repertoire, design cognition, mid-level knowledge, pattern languages, precedents

\section{INTRODUCTION}

Many of the design instructors in our institute express an ambivalent relationship with examples. They acknowledge the power of examples to illustrate abstract design principles and concepts, but they are also -at times- wary of providing them, fearing that they may restrict their students' thinking. With regard to conceptual knowledge, for instance, instructors fear that examples used to illustrate a general principle will prompt students to reduce that principle to exactly those examples. The ambivalence pertains specifically to using examples of existing designs. Instructors feel that a discussion of existing solutions to the problems presented to their students may lead to design fixation ([10]Error! Reference source not found.): as a result of discussing those solutions the range of possible solutions students can imagine will be limited. This last fear is also shared by students: sometimes students implore their instructors to not provide examples for fear of 'getting stuck' and not being able to be 'original' anymore. However, in our view these reservations rests on a persistent set of misconceptions about design cognition.

In contrast to teachers' and students' models of design, design cognition literature stresses the importance of existing solutions (often called precedents) and intermediate solution proposals (known as propositions) as a central part of design reasoning. Unfortunately, the question of how such solutionoriented thinking is taught has received less scholarly attention. This is remarkable, for if it is important for designers to quickly dream up and adapt solutions in a design process, one would expect a rich discourse in design education on how we prepare for this challenge. Teaching existing designs properly may be key. Instructors need guidance on what existing designs they must discuss with students, how to discuss them, how to teach students to appreciate them, how to draw from such examples creatively, and how to test students' ability to do so. However, this educational discourse seems underdeveloped.

In this paper, we try to redress the balance by introducing the notion of solution repertoire which we define as "the competence of appreciating and handling solutions in one's design discipline and to use them as an anchor point for design-relevant knowledge that goes beyond the anecdotal experience". By doing this, we hope to stress the importance of teaching solutions in design education and to be more explicit about the different types of knowledge that complement solutions and act as a stepping-stone to the mastery that needed to speak of a repertoire. In this paper, after a brief review of the design cognition literature, we analyse the educational benefit of the notion of solution repertoire. This helps to critically evaluate some of our practices with regard to teaching solutions. We end with conclusions and an outlook on future developments. 


\section{SOLUTION-ORIENTED THINKING IN THE DESIGN PROCESS}

In a foundation study in design cognition, Brian Lawson compared thinking strategies of students in physics and architecture. Confronted with a problem-solving task, physics students tended to focus their analysis on the problem and the problem constraints, whereas design students laid out several different solutions and tried to improve on them [5]. These disciplinary differences spun off a large body of literature on solution-oriented thinking in design. Indeed, studies of design in action, sketched vividly by Schön in his vignette of design as a reflective activity [6], show how designers follow a line of reasoning in which they propose alternative solutions (propositions) to a problem and evaluate and appreciate each one of them with respect to the problem and their design knowledge and sense of aesthetics. This reflective process was characterized by Dorst \& Cross in the early 2000's, as an iterative movement between the problem space and the solution space [7]. It appears many designers start this process in the solution space. Amongst others, Darke has shown that designers use solution templates as a primary generator within their creative processes [1]. In her quest to pinpoint the design strategy of arrived architects, she found that they use two types of generators for their designs. First, they use solution examples and their experiences from previous projects to start their thinking [1], and next they develop that thinking with the help of a continuous dialogue between their current design problem and their initial examples [20]. Findings like these posed a serious challenge to the then dominant analysissynthesis model for design, in which analysis and synthesis were considered as distinct phases in design. It is commonly assumed that students acquire the basics of solution-oriented thinking during their studio classes, where they get to solve real-life projects in a classroom situation [2], which is a dominant model of design education. We do not think this is the complete story. The studio model is a reasonable response to challenge of practicing solution-oriented thinking, but it neglects the question where the solutions students come up with come from in the first place. What is the knowledge base that students employ making all those propositions? The likely answer is that students draw from examples of design that they know either from their own experience or from design education and adapt them to the particular design challenge. Indeed, we know that designers do it this way. Designers are known for their habits of creating collections of inspirational materials [19] and many authors have suggested that existing solutions (precedents [3]) play a prominent role in the conception of novel designs. This is not the same for students. A study by Gray \& Bollinger showed that while junior designers, too, use precedents, they are not aware of this [9] and as a result their knowledge about precedents does not trivially translate into design schemata. In other words: students need to be taught both that they can start from design exemplars and how such exemplars can inform their design. Solution-oriented design strategies may be nurtured in the studio, but they need to be seeded by our treatment of existing designs. If we ask what the 'content' of design thinking [8] is, the answer minimally should include: the existing solutions within one's design discipline.

\section{TOWARDS A NOTION OF SOLUTION REPERTOIRE}

\subsection{The hierarchical model of design knowledge}

How do design teachers conceptualize design knowledge? Recurring ambivalence with regard to the use of giving examples in teaching may have its roots in teachers' thinking about knowledge structures in general and those of the discipline in particular [10].

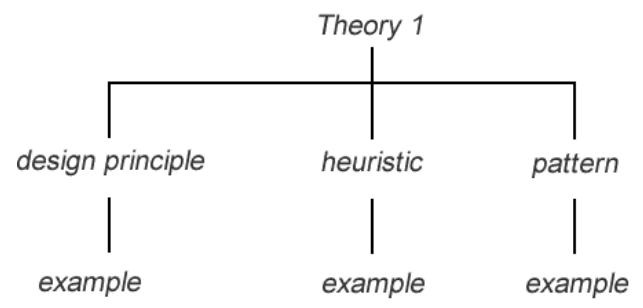

Figure 1. Classical conception of knowledge as a tree: solutions are examples of more important other types of knowledge

Our informal observation is that most instructors still conceptualize (design) knowledge as a hierarchical structure, where high-level theoretical concepts are first operationalized into mid-level knowledge [18] 
and then into concrete designs. Mid-level knowledge is knowledge that resides somewhere between abstract theories and concrete designs. Common examples are design guidelines, heuristics, strong concepts [12] and design patterns [13]. Existing designs (precedents) are subsequently selected for their ability to illustrate the higher-level concepts. This hierarchy is illustrated in Figure 1.

This conception of design knowledge is, however, problematic for three reasons. Firstly, the hierarchical model favours abstract, disembodied, knowledge over concrete examples. As stated in the introduction, this is not in line with how practitioners' value and use examples, while it does have an effect on the priorities, we are setting in our design programmes. The amount of attention paid by curriculum design to establish the 'body of knowledge' greatly outweighs the attention spent on the 'body of important design exemplars.

The second problem is of a more conceptual kind: by being featured as 'mere examples' of higher notions, the design examples are related to those higher notions, but never explicitly to each other. Students learn how an interface is an example of a design heuristic, and how a different interface implements a particular design pattern, but they are not asked to relate these different examples to each other. Consequently, students are not taught how to navigate the solution space 'horizontally': they are not trained to think about how solution types might be grouped together, how there may be families of solutions, and, therefore, they receive little help in understanding and navigating the solution space.

Finally, the hierarchical model presupposes a unilateral relationship between theory and design - as if design can be deduced from theory. If students need to navigate the solution space, theory may play an important role, but the relationship between design and theory is never unilateral. In their piece on annotated portfolios [9] Bolin E. and Gray C. M. (2018). Use of precedent as a narrative practice in design learning. In Educational Technology and Narrative (pp. 259-270). Springer, Cham.

[10] Hativa N. and Goodyear P. (2002). Teacher Thinking, Beliefs and Knowledge in Higher Education. Kluwer, Academic Publishers.

[11] Löwgren J. (2013). Annotated portfolios and other forms of intermediate-level knowledge. Interactions, 20(1), 30-34.

[12] Höök K. and Löwgren J. (2012). Strong concepts: Intermediate-level knowledge in interaction design research. ACM Transactions on Computer-Human Interaction (TOCHI), 19(3), 1-18.

[13] Alexander C. The timeless way of building (Vol. 1). New York: Oxford University Press. 1979

[14], Gaver and Bowers show that, while designs and the thinking about design form an intimate yet complex relationship, in fact, designs are 'underdetermined' by theory. Theoretical convictions can lead to a wide set of designs. However, the reverse is also true: 'theorizing' is underdetermined by design. That is, each design can be understood from a multitude of theories [9]Bolin E. and Gray C. M. (2018). Use of precedent as a narrative practice in design learning. In Educational Technology and Narrative (pp. 259-270). Springer, Cham.

[10] Hativa N. and Goodyear P. (2002). Teacher Thinking, Beliefs and Knowledge in Higher Education. Kluwer, Academic Publishers.

[11] Löwgren J. (2013). Annotated portfolios and other forms of intermediate-level knowledge. Interactions, 20(1), 30-34.

[12] Höök K. and Löwgren J. (2012). Strong concepts: Intermediate-level knowledge in interaction design research. ACM Transactions on Computer-Human Interaction (TOCHI), 19(3), 1-18.

[13] Alexander C. The timeless way of building (Vol. 1). New York: Oxford University Press. 1979 [14]. To build the epistemic fluency [15] needed to flexibly understand designs from a multitude of theoretical viewpoints and vice versa, the hierarchical model is simply insufficient.

\subsection{The embodied model of design knowledge (i.e., a solution repertoire)}

An alternative way of thinking of the role of solutions in a design curriculum is illustrated in Figure 2: 


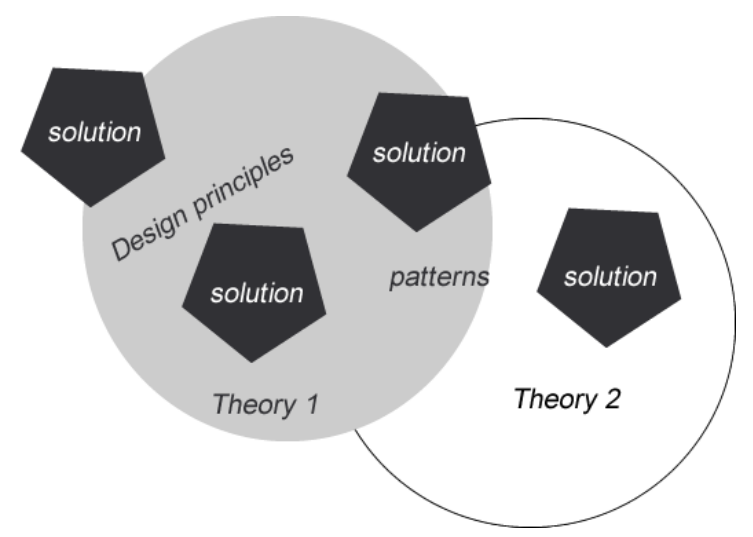

Figure 2. Alternative conception of knowledge:

solutions are central concepts interconnected by higher level knowledge constructs: a solution repertoire

This picture, in contrast, highlights solutions as the central anchor point of multiple bodies of abstract knowledge. They are not examples of that knowledge, they can be viewed through different theoretical lenses. Curricula can be built around carefully established sets of exemplary designs that are used as stepping-stones in a somewhat amorphous theoretical space of families of designs, mid-level knowledge constructs and high-level theories. This reversal of the hierarchical picture is not intended to dismiss the importance of theoretical constructs in design - we think theory is immensely important - but to redress the balance between thinking about design in terms of disembodied concepts and the concrete designs that form the embodiment of those ideas. For instance, when the concept of Cialdini's six principles of influences is explained to junior designers, they were provided with examples of live commercial designs that each implemented a principle. However, students would try to understand the theoretical principles by learning the examples. They lost sight, or never gained sight, of how each of the examples embodied more than one principle, and how the examples were actually related to each other in many other ways as well. They were and should have always been regarded as more than just examples of something more important.

Rather than stressing the 'level' of abstraction, with the implicit notion that more abstract is somehow better, the proposal in Figure 2 stresses the link of theoretical notions with concrete designs. The idea of a solution repertoire suggests that theories need to be taught in close relation to specific design exemplars. Abstract ideas about designs make sense in the presence of active knowledge of particular designs that are subject to those abstractions. The designs are central, and the abstractions are needed to think about these designs. The notion of a solution repertoire also stresses the active and personal nature of such solution-oriented knowledge. A repertoire consists of solutions that are internalized to such an extent that a designer can develop a personal style by fluently calling on them and then adapting solutions to their needs and the needs of the problem they are facing. Finally, it celebrates the multiplicity proposed by Gaver \& Bowers [9]Bolin E. and Gray C. M. (2018). Use of precedent as a narrative practice in design learning. In Educational Technology and Narrative (pp. 259-270). Springer, Cham.

[10] Hativa N. and Goodyear P. (2002). Teacher Thinking, Beliefs and Knowledge in Higher

Education. Kluwer, Academic Publishers.

[11] Löwgren J. (2013). Annotated portfolios and other forms of intermediate-level knowledge. Interactions, 20(1), 30-34.

[12] Höök K. and Löwgren J. (2012). Strong concepts: Intermediate-level knowledge in interaction design research. ACM Transactions on Computer-Human Interaction (TOCHI), 19(3), 1-18.

[13] Alexander C. The timeless way of building (Vol. 1). New York: Oxford University Press. 1979

[14]. In our view, 'knowing' a design means appreciating (and critiquing) it from multiple theoretical viewpoints which are easily switched.

\section{THE PRACTICE OF TEACHING SOLUTION REPERTOIRE}

\subsection{Introducing the notion of solution repertoire into our educational programmes}

The term solution repertoire resonates with colleagues, at least in the sense that they share the aspiration to train designers who master a set of solutions and can fluently use them to generate new designs. One step towards furthering the notion of solution repertoire is the realization that the role of solutions 
changes with the different phases of the design process. In this sense, the mapping of theory functions to a generalized version of the design cycle by van Turnhout et al. [16] turns out to be a helpful aid in our understanding of the use of solutions in design. In this section, we discuss the different roles solutions assume in each design phase.

\subsection{Solution repertoire as a strategy for (gateway to) understanding problems}

By its very definition, a solution is connected to a problem - a solution is always a solution 'for something'. This means solutions can contribute to the description and explanation [16] of a design situation and aid in what is commonly understood as the analysis phase in design where students build an understanding of the current situation. Following Schön [6] and Dorst [7], the ability to use solutions as a gateway to build a stronger understanding of the problem space is crucial. But in our educational programmes, students are seldom explicitly trained to make this step. The analysis-synthesis model [4] is still very dominant and students are mostly taught to approach the problem with only armed with analytic tools. Teachers wrongly assume that, if students are trained not to think about the current design or alternative designs proposals, they will overcome fixation and will be more creative later in the process.

A better way to teach the thinking step that is needed to move from the solution space to the problem space, may be to use design critique as a gateway to building an understanding of the design situation. An example is the vision in interaction technique proposed by Pasman et al. [17] who use a specific interaction design and then systematically train students to use it to describe and explain the situation the current design is responding to, in increasing layers of abstraction. This bottom-up approach may form a better training to build the type of solution-oriented analysis skills that are needed for design than the top-down, disembodied approach that is propagated by the analysis-synthesis model.

Another way to teach students to use solutions as a gateway to problems, is to use benchmarking exercises. Creating a structured benchmark of existing solutions for a given design problem helps students to move from thinking about a single solution to a solution family, with many variants. The structure of a design benchmark typically also mirrors hidden structures in the problem space.

\subsection{Solutions as a strategy for (gateway to) explicating design aspirations}

As stated in the introduction, existing design solution examples can be used as a stepping-stone to novel ideas and concepts and this use of a design precedent is an important skill for designers. One approach to teach this generative role of design precedent is to teach solution-oriented design systems, such as pattern languages [12] Höök K. and Löwgren J. (2012). Strong concepts: Intermediate-level knowledge in interaction design research. ACM Transactions on Computer-

Human Interaction (TOCHI), 19(3), 1-18.

[13] and design typologies Error! Reference source not found.. Although we make use of such systems, we are still struggling with building a meta-cognitive understanding of this material.

This problem is also reported by Boling \& Gray [9]. They require their students to actively seek out and consciously use design precedents, and subsequently reflect on how they use those precedents. Their dilemma was, however, that students had a hard time understanding that they already use precedents, a lack of awareness that inhibited students to account for and reflect on their use of precedents. Generative practices such as requiring students to maintain a notebook with design ideas, sketches and insights or brainstorm techniques forcing students to come up with new ways to handle existing objects are useful to train the habit of pursuing multiple solution directions and thinking lines in parallel, but they do not directly help students to connect their ideas with higher level knowledge.

In van Turnhout et al.'s [16] view, the generative theory function is closely linked with the aspirational function. In order to understand the solution space, different design alternatives need to be understood in terms of underlying values and ideals. This links to Gaver's notion of aesthetic accountability: "Instead design can be defined by the aesthetic accountability of its outputs. Aesthetic here does not refer to a judgement of beauty, but to a holistic assessment whether a design 'works', functionally, conceptually, culturally, and aesthetically (in the narrower sense)." [18, pp194]. When it comes to the generative use of precedents in our educational programme, we believe we are paying enough attention to getting students to propose multiple alternative solutions, but not enough attention to teaching the student to account for the underlying values behind these designs. An exception is an exercise in which we ask students to identify a role model (i.e., a famous designer) in their specific profession and to analyse artefacts of their work to get a feel for how the elements in the design work 
and start recognizing a personal style. We must expand on this practice and find more opportunities to train students to relate design alternatives to the underlying value systems.

\subsection{Solutions as a strategy for (gateway to) finding effective mechanisms in design}

A third reason to teach 'example solutions/precedents' in the educational programme, is that they embody proven rules of thumb, requirements, design patterns and guidelines. We convey ideas about what is effective using illustrative exemplars. The way we teach precedents as illustration of effectiveness of guidelines is subject to the critique in the previous section. We act as if design guidelines can be straightforwardly translated into effective design using a limited set of well-chosen precedents; implicitly conveying the linear, top-down, notion of design we are trying to avoid.

At some places, we have adopted an approach that is more in line with the complex thinking needed to incorporate different design prescriptions into a single design, thus celebrating the multiplicity of the solution-theory relationship. For example, we used annotated portfolios [14] proposed by Gaver and Bowers as a way to encourage students to spot design guidelines in the wild. Students had to create an annotated portfolio of original examples - none that were provided in class - for the application of psychological principles, such as social proof, or figure-background gestalt principles, in existing interactive media designs.

\section{CONCLUSIONS AND DISCUSSION}

In this paper, we have argued that design 'solutions' such as iconic designs, archetypes and design patterns, ought to be recognized as crucial forms of design knowledge: a necessary element of the students' 'solution repertoire'. However, well-known precedents in our field are insufficiently treated as such in academic (interaction) design programmes. By default, they are treated as examples of something else (i.e., a theory, a period), rather than as crucial elements of the knowledge base of aspiring designers in their own right. In this paper, we turned the tables and consider other forms of knowledge as instrumental to the mastery of solutions. This change of perspective allowed us to re-examine the ways we currently teach precedents to students, how we can teach them more effectively and how we can make them more explicit in our curricula.

Our current analysis reveals that our efforts to teach design solutions are isolated attempts in individual courses or initiated by a single teacher without follow-up. Design solutions are hardly used as a gateway to understand the problems we need to solve. They are used as a generative force in design, but with insufficient attention to the underlying values and design ideals - i.e., with insufficient theoretical understanding of the aspirations of those designs. We do use design solutions to teach design guidelines, but we can improve in doing so in a way that celebrates the multiple ways theory connects to design. We need to strengthen the students' understanding of design solutions in different ways. Knowing a solution, i.e., mastering a solution, means understanding it from different theoretical lenses and having ability to switch fluently between such knowledge ties.

We also think there is a need for a more systematic approach to build 'a solution repertoire' across the curriculum. Individual teachers already provide assignments that help students appreciate but we are in need of shared vision, a solution repertoire of the discipline, so to say. In the end students need to build a personal solution repertoire but this needs to be fed by the repertoire of the discipline. For this we need to extend the view on how precedents relate to conceptual knowledge and how this can be translated in productive exercises for students. We can implement a skills track in which students are taught to consider design solutions not just as solutions to an anecdotal problem, but in which they learn to categorize them based on relevant characteristics and to understand how each category (family) affords solutions for different kind of problems. Probably a good place to start would be to compile a 'canon of design solutions', including their family relations and family traits. Students need to understand how sets of design solutions are structured, and they need to learn to restructure those insightfully. This structuring and restructuring process fuels an intimate understanding of design solutions and an appropriation practice and design proficiency. Like any other skill: it takes a concerted and continued effort to make the concept sink in and make teachers and students understand that this goes beyond learning incidental examples by heart and beyond merely understanding the concepts that the examples are meant to illustrate. Existing design solutions are never merely examples.

\section{REFERENCES}

[1] Chrysikou E. G. and Weisberg R. W. (2005). Following the wrong footsteps: Fixation effects of 
pictorial examples in a design problem-solving task. Journal of Experimental Psychology: Learning, Memory, and Cognition, 31, 1134-1148.

[2] Lawson B. (2018). The Design Student's Journey: Understanding how Designers Think. Routledge.

[3] Pasman G. Designing with precedents (Unpublished doctoral dissertation), Delft University of Technology, Delft, NL, 2003.

[4] Darke J. The primary generator and the design process. Design Studies, No. 1, 1979, 36-44

[5] Lawson B. R. Cognitive strategies in architectural design. Ergonomics, 22, 1979, 59-68.

[6] Schön D. The reflective practitioner. New York, Basic Books, 1983

[7] Dorst K. and Cross N. Creativity in the design process: co-evolution of problem - solution. Design Studies, 22, 2001, 425-437

[8] Gra C. M., Seife C. M., Yilma S., Dal S. R., and Gonzalez R. (2016). What is the content of "design thinking"? Design heuristics as conceptual repertoire. International Journal of Engineering Education, 32

[9] Bolin E. and Gray C. M. (2018). Use of precedent as a narrative practice in design learning. In Educational Technology and Narrative (pp. 259-270). Springer, Cham.

[10] Hativa N. and Goodyear P. (2002). Teacher Thinking, Beliefs and Knowledge in Higher Education. Kluwer, Academic Publishers.

[11] Löwgren J. (2013). Annotated portfolios and other forms of intermediate-level knowledge. Interactions, 20(1), 30-34.

[12] Höök K. and Löwgren J. (2012). Strong concepts: Intermediate-level knowledge in interaction design research. ACM Transactions on Computer-Human Interaction (TOCHI), 19(3), 1-18.

[13] Alexander C. The timeless way of building (Vol. 1). New York: Oxford University Press. 1979

[14] Gaver B. and Bowers J. (2012). Annotated portfolios. interactions, 19(4), 40-49.

[15] Markauskaite L. and Goodyear P. (2017). Epistemic fluency and professional education. Dordrecht: Springer.

[16] van Turnhout K., Jacobs M., Losse M., van der Geest T. and Bakker R. (2019) A Practical Take on Theory in HCI. White Paper. HAN University of Applied Sciences.

[17] Pasman G., Boess S., and Desmet P. (2011). Interaction vision: expressing and identifying the qualities of user-product interactions. In DS 69: Proceedings of E\&PDE 2011, the 13th International Conference on Engineering and Product Design Education, London, UK, 08.09.09. 2011 (pp. 149-154).

[18] Joost G. et al. eds. Design as Research: Positions, Arguments, Perspectives. Birkhäuser, 2016.

[19] Keller A. I., Pasman G. J., and Stappers P. J. (2006). Collections designers keep: Collecting visual material for inspiration and reference. CoDesign, 2(01), 17-33.

[20] Goldschmidt G. (1991). The dialectics of sketching. Creativity research journal, 4(2), 123-143. 